\title{
High-Flow Nasal Cannula Versus Conventional Oxygen Therapy After Endotracheal Extubation: A Randomized Crossover Physiologic Study
}

\author{
Nuttapol Rittayamai MD, Jamsak Tscheikuna MD, and Pitchayapa Rujiwit MD
}

\begin{abstract}
OBJECTIVE: Compare the short-term benefit of high-flow nasal cannula (HFNC) with nonrebreathing mask in terms of change in dyspnea, physiologic variables, and patient comfort in subjects after endotracheal extubation. METHODS: A randomized crossover study was conducted in a 10-bed respiratory care unit in a university hospital. Seventeen mechanically ventilated subjects were randomized after extubation to either Protocol A (applied HFNC for $30 \mathrm{~min}$, followed by non-rebreathing mask for another $\mathbf{3 0}$ min) or Protocol B (applied non-rebreathing mask for 30 min, followed by HFNC for another $30 \mathrm{~min}$ ). The level of dyspnea, breathing frequency, heart rate, blood pressure, oxygen saturation, and patient comfort were recorded. The results were expressed as mean $\pm \mathrm{SD}$, frequency, or percentage. Categorical variables were compared by chi-square test or Fisher exact test, and continuous variables were compared by dependent or paired $t$ test. Statistical significance was defined as $P<.05$. RESULTS: Seventeen subjects were divided into 2 groups: 9 subjects in Protocol A and 8 subjects in Protocol B. The baseline characteristics and physiologic parameters before extubation were not significantly different in each protocol. At the end of study, HFNC indicated less dyspnea $(P=.04)$ and lower breathing frequency $(P=.009)$ and heart rate $(P=.006)$ compared with non-rebreathing mask. Most of the subjects $(88.2 \%)$ preferred HFNC to non-rebreathing mask. CONCLUSIONS: HFNC can improve dyspnea and physiologic parameters, including breathing frequency and heart rate, in extubated subjects compared with conventional oxygen therapy. This device may have a potential role for use after endotracheal extubation. Key words: high-flow nasal oxygen cannula; non-rebreathing mask; endotracheal extubation; oxygen therapy-noninvasive ventilation. [Respir Care 2014;59(4):485-490. (C) 2014 Daedalus Enterprises]
\end{abstract}

\section{Introduction}

Oxygen therapy is essential in the management of patients who have a respiratory problem, including after en-

Drs Rittayamai and Tscheikuna are affiliated with the Division of Respiratory Diseases and Tuberculosis, Department of Medicine, Faculty of Medicine Siriraj Hospital, Mahidol University, Bangkok, Thailand. Dr Rujiwit is affiliated with the Division of Pulmonary and Pulmonary Critical Care Disease, Department of Medicine, Faculty of Medicine, Thammasat University, Pathum Thani, Thailand.

Dr. Rittayamai presented this paper at the 25th European Society of Intensive Care Medicine Annual Congress, held October 13-17, 2012, in Lisbon, Portugal

The authors have disclosed no conflicts of interest.

Correspondence: Nuttapol Rittayamai MD, Division of Respiratory Diseases and Tuberculosis, Department of Medicine, Faculty of Medicine dotracheal extubation. Oxygen supply via face mask with bag is routinely used in these patients, but this method may be inadequate in some patients, especially if they require a high inspiratory flow (this may be from $30 \mathrm{~L} / \mathrm{min}$ up to $120 \mathrm{~L} / \mathrm{min}$ in patients with acute respiratory failure), ${ }^{1}$ whereas non-rebreathing mask can provide a maximum flow of only up to $10-15 \mathrm{~L} / \mathrm{min}$. Furthermore, oxygen supply by non-rebreathing mask will be variable depending on the flow of oxygen and the patient's breathing pattern. $^{2}$

High-flow nasal cannula (HFNC) is a new technological device in a high-flow oxygen system that consists of an

Siriraj Hospital, Mahidol University, 2 Prannok Road, Bangkok Noi, Bangkok 10700, Thailand. E-mail: nuttapol.rit@mahidol.ac.th.

DOI: $10.4187 /$ respcare.02397 
air-oxygen blender, which allows from 0.21 to $1.00 \mathrm{~F}_{\mathrm{IO}_{2}}$ and which generates a gas flow of up to $55 \mathrm{~L} / \mathrm{min}$, and a heated humidification system, ${ }^{3}$ which may have several advantages in reducing the work of breathing. This method can wash out pharyngeal dead space, reduce nasopharyngeal resistance, create some PEEP and constant $\mathrm{F}_{\mathrm{IO}_{2}}$, and facilitate secretion clearance from humidified gas. ${ }^{4} \mathrm{HFNC}$ has been evaluated in many groups, including healthy subjects, patients with acute respiratory failure, and patients recovering from post-cardiac surgery. Extubated patients will need a high inspiratory flow and adequate oxygen supplementation, so after extubation, a high flow of oxygen may be necessary to compensate for the work of breathing; thus, HFNC may have a role in this situation via many mechanisms that have been discussed previously. However, in the medical literature, there are limited data on the benefit of HFNC in recently extubated patients. Thus, the primary objective of this study was to compare HFNC with non-rebreathing mask in extubated patients in terms of change in dyspnea, physiologic variables, and patient comfort.

\section{Methods}

\section{Study Design and Population}

A randomized, non-blinded, crossover study was conducted from August 2011 to December 2011 in a 10-bed respiratory intensive care unit in the Division of Respiratory Diseases and Tuberculosis, Department of Medicine, Faculty of Medicine Siriraj Hospital, Bangkok, Thailand, to investigate the benefits of HFNC in terms of change in dyspnea, physiologic variables, and patient comfort and to compare them with non-rebreathing mask with bag after endotracheal extubation. This study was approved by the Siriraj Institutional Review Board and the subjects or a subject's next of kin gave informed consent.

Mechanically ventilated subjects who were $\geq 18$ years of age, successfully weaned by spontaneous breathing trial (SBT) with oxygen T-piece or low level of pressure support for $120 \mathrm{~min}$, and ready for endotracheal extubation were included. Subjects with hemodynamic instability or a decreased level of consciousness, subjects who lacked cooperation, tracheostomized patients, and pregnant women were excluded.

\section{Device Description}

The HFNC device (Optiflow, Fisher \& Paykel Healthcare, Auckland, New Zealand) consists of an air-oxygen blender, which allows from 0.21 to $1.00 \mathrm{~F}_{\mathrm{IO}_{2}}$ and which generates a gas flow of up to $55 \mathrm{~L} / \mathrm{min}$, and a heated humidification system (MR850 heated humidifier, Fisher \& Paykel Healthcare). The gas mixture at $37^{\circ} \mathrm{C}$ is deliv-

\section{QUICK LOOK}

\section{Current knowledge}

High-flow nasal cannula can improve oxygenation by delivering humidified oxygen and decrease the ventilatory requirement by washing out dead space of the upper airway.

\section{What this paper contributes to our knowledge}

In a group of patients following extubation, the use of high-flow oxygen via nasal cannula reduced dyspnea and resulted in a lower breathing frequency and heart rate compared with oxygen via non-rebreathing mask.

ered via a single-limb heated inspiratory circuit to the patient through a nasal cannula. Conventional oxygen therapy was applied via a non-rebreathing mask at an oxygen flow of $6-10 \mathrm{~L} / \mathrm{min}$.

\section{Protocol}

In our respiratory ICU (with a nurse-to-patient ratio of $1: 1.5$ and expertise in caring for patients with respiratory problems such as acute respiratory failure and difficult weaning), weaning is guided by a non-mandatory protocol that is executed by resident trainees and pulmonologists. In general, subjects with stable hemodynamics (with mean arterial pressure $\geq 65 \mathrm{~mm} \mathrm{Hg}$ and not receiving vasopressors) and adequate oxygenation $\left(\mathrm{S}_{\mathrm{pO}_{2}}>92 \%\right.$ with $\mathrm{F}_{\mathrm{IO}_{2}} \leq 0.4$, PEEP $\leq 8 \mathrm{~mm} \mathrm{Hg}$, and $\mathrm{P}_{\mathrm{aO}_{2}} / \mathrm{F}_{\mathrm{IO}_{2}} \geq 150$ ) are weaned by SBT with oxygen T-piece or low-level pressure support for $120 \mathrm{~min}$. Subjects who successfully complete the SBT are considered for endotracheal extubation.

After endotracheal extubation, the subjects were randomized into two protocols. In Protocol A, oxygen was delivered via HFNC using an initial inspiratory flow of $35 \mathrm{~L} / \mathrm{min}$, and $\mathrm{F}_{\mathrm{IO}_{2}}$ was adjusted to achieve $\mathrm{S}_{\mathrm{pO}_{2}}$ of at least $94 \%$ within the first $5 \mathrm{~min}$ and to maintain this setting for $30 \mathrm{~min}$, followed by non-rebreathing mask at $6-10 \mathrm{~L} / \mathrm{min}$ to achieve $\mathrm{S}_{\mathrm{pO}_{2}} \geq 94 \%$ for another $30 \mathrm{~min}$. We used a starting flow of $35 \mathrm{~L} / \mathrm{min}$ and a study period of $30 \mathrm{~min}$ in each intervention based on previous studies ${ }^{5-7}$ that demonstrated a better performance of HFNC using a flow of $35 \mathrm{~L} / \mathrm{min}$ and the detection of physiologic differences between study groups during this time period. In Protocol B, the subjects began with non-rebreathing mask for $30 \mathrm{~min}$ and then switched to HFNC for $30 \mathrm{~min}$. After completing the study, the type and level of oxygen supplementation were adjusted by the intensive care physicians, who have this responsibility. 


\section{Data Collection}

Baseline demographic and clinical data before endotracheal extubation were collected. After extubation, the level of dyspnea and patient comfort were assessed by using a visual analog scale ranging from 0 to 10 . The breathing frequency, heart rate, blood pressure, and $\mathrm{S}_{\mathrm{pO}_{2}}$ were recorded immediately after extubation and then at 5, 10, 15, and 30 min during each period of intervention. At the end of the study period, the subjects were asked whether they preferred HFNC or non-rebreathing mask.

\section{Outcome}

The primary outcome was the improved effects of HFNC in reducing dyspnea after endotracheal extubation compared with non-rebreathing mask. The secondary outcomes were effects on the physiologic variables (breathing frequency, heart rate, and mean arterial pressure) and patient comfort.

\section{Statistical Analysis}

The estimated sample size was 17 subjects based on a previous study ${ }^{5}$ of HFNC in acute respiratory failure, and we expected that HFNC could improve dyspnea in extubated subjects at $25 \%$ compared with non-rebreathing mask at a power of $90 \%$ with a level of significance of .05 . All statistical analyses were performed using SPSS 15 (SPSS Inc., Chicago, Illinois). The results were expressed as mean $\pm \mathrm{SD}$, frequency, or percentage. Categorical variables were compared by chi-square test or Fisher exact test, and continuous variables were compared by dependent or paired $t$ test. Statistical significance was defined as $P<.05$.

\section{Results}

\section{General Characteristics}

Twenty-five subjects were recruited, and 17 subjects were included during the study period ( 8 subjects were excluded because they could not tolerate SBT for $120 \mathrm{~min}$ ). The baseline characteristics of 17 subjects are shown in Table 1 . The mean age was $66.8 \pm 13.8$ years, and the most common cause of respiratory failure was COPD exacerbation $(6 / 17,35.2 \%)$. Nine subjects were enrolled in Protocol A, and 8 subjects were enrolled in Protocol B. There were no differences in baseline characteristics and physiologic parameters before extubation between the two protocols (Table 2).
Table 1. General Characteristics

\begin{tabular}{lc}
\hline \hline Subject, $n$ & 17 \\
Age, mean \pm SD y & $66.8 \pm 13.8$ \\
Male, $n(\%)$ & $10(58.8)$ \\
Comorbidities, $n(\%)$ & \\
$\quad$ Respiratory & $9(52.9)$ \\
Cardiovascular & $8(47.1)$ \\
Hypertension & $8(47.1)$ \\
Chronic kidney disease & $5(29.4)$ \\
Diabetes mellitus & $5(29.4)$ \\
Malignancy & $2(11.8)$ \\
Cerebrovascular disease & $1(5.9)$ \\
SAP II score, mean \pm SD & $30.9 \pm 4.4$ \\
Etiology of respiratory failure, $n(\%)$ & \\
COPD exacerbation & $6(35.2)$ \\
Hospital-acquired pneumonia & $4(23.5)$ \\
Community-acquired pneumonia & $2(11.8)$ \\
Congestive heart failure & $2(11.8)$ \\
Massive hemoptysis & $1(5.9)$ \\
Empyema thoracis & $1(5.9)$ \\
Aspiration pneumonia & $1(5.9)$ \\
Duration of intubation, mean \pm SD d & $7.1 \pm 4.4$
\end{tabular}

SAPS II = Simplified Acute Physiology Score II

Table 2. Physiologic Parameters Before Extubation for Protocols A and $\mathrm{B}$

\begin{tabular}{llll}
\hline \hline \multicolumn{1}{c}{ Parameter } & $\begin{array}{c}\text { Protocol A } \\
(\text { Mean } \pm \mathrm{SD})\end{array}$ & $\begin{array}{c}\text { Protocol B } \\
(\text { Mean } \pm \mathrm{SD})\end{array}$ & $P$ \\
\hline Breathing frequency, breaths/min & $20.3 \pm 4.5$ & $21.7 \pm 3.8$ & .98 \\
Mean arterial pressure, mm Hg & $95.1 \pm 14.1$ & $97.6 \pm 12.9$ & .81 \\
Heart rate, beats/min & $93.1 \pm 8.2$ & $88.5 \pm 8.4$ & .89 \\
Oxygen saturation, \% & $98.5 \pm 2.9$ & $98.4 \pm 1.7$ & .55
\end{tabular}

Protocol A = high-flow nasal cannula, followed by non-rebreathing mask Protocol B = non-rebreathing mask, followed by high-flow nasal cannula

\section{Clinical Parameters and Outcomes}

The mean total gas flow in the HFNC group and that in the non-rebreathing mask group were 36.8 and $8.0 \mathrm{~L} / \mathrm{min}$, respectively. Use of HFNC was associated with significant reduction in dyspnea compared with non-rebreathing mask, and the benefit of HFNC was demonstrated at $10 \mathrm{~min}$ after applying the device until the end of study (Fig. 1). Dyspnea scores at $30 \mathrm{~min}$ after applying HFNC and nonrebreathing mask were $1.6 \pm 1.2$ and $2.9 \pm 1.5$, respectively $(P=.04)$ (Table 3 ).

HFNC demonstrated significant benefits in terms of heart rate and breathing frequency compared with non-rebreathing mask (Fig. 2). At the end of the study, heart rate and breathing frequency obtained with HFNC and nonrebreathing mask were $89.5 \pm 9.5$ and $95.4 \pm 10.4$ beats/ 


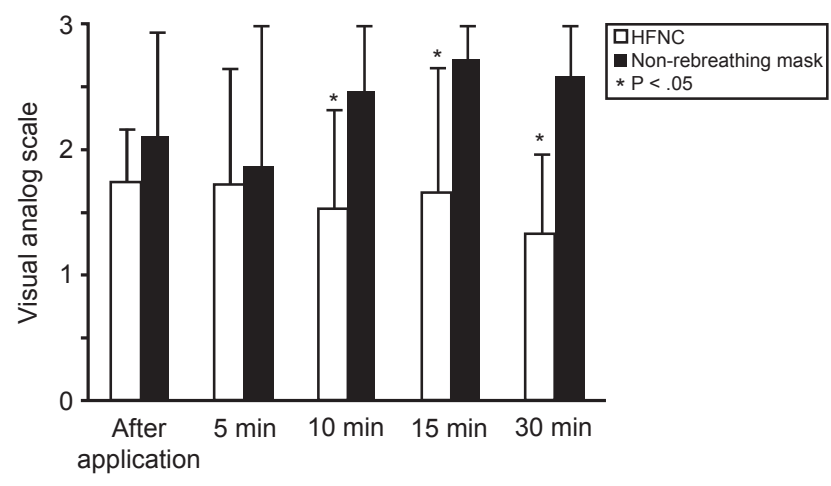

Fig. 1. Change in dyspnea. HFNC = high-flow nasal cannula

Table 3. Clinical and Physiologic Parameters for High-Flow Nasal Cannula and Non-Rebreathing Mask at the End of Intervention

\begin{tabular}{|c|c|c|c|}
\hline Parameters & $\begin{array}{c}\text { HFNC } \\
(\text { Mean } \pm \text { SD) }\end{array}$ & $\begin{array}{l}\text { Non-rebreathing Mask } \\
\quad(\text { Mean } \pm \text { SD })\end{array}$ & $P$ \\
\hline \multicolumn{4}{|l|}{ Subjective evaluation } \\
\hline Dyspnea score & $1.6 \pm 1.2$ & $2.9 \pm 1.5$ & $.04 *$ \\
\hline Comfort score & $1.4 \pm 0.9$ & $1.9 \pm 1.1$ & .07 \\
\hline \multicolumn{4}{|l|}{$\begin{array}{l}\text { Respiratory and gas } \\
\text { exchange variables }\end{array}$} \\
\hline Oxygen saturation, $\%$ & $98.2 \pm 2.1$ & $98.8 \pm 1.8$ & .44 \\
\hline $\begin{array}{l}\text { Breathing frequency, } \\
\text { breaths/min }\end{array}$ & $19.8 \pm 3.2$ & $23.1 \pm 4.4$ & $.009 *$ \\
\hline \multicolumn{4}{|l|}{ Hemodynamic variables } \\
\hline $\begin{array}{l}\text { Mean arterial pressure, } \\
\text { mm Hg }\end{array}$ & $95.8 \pm 12.3$ & $97.5 \pm 10.2$ & .32 \\
\hline Heart rate, beats/min & $89.5 \pm 9.5$ & $95.4 \pm 10.4$ & $.006 *$ \\
\hline$*_{*}$ & & & \\
\hline
\end{tabular}

min, respectively $(P=.006)$, and $19.8 \pm 3.2$ and $23.1 \pm$ 4.4 breaths/min, respectively $(P=.009)$. The subjects in the HFNC group were more comfortable than those in the non-rebreathing mask group, but this parameter was not significant $(P=.07)$, and most of the subjects preferred HFNC rather than non-rebreathing mask $(15 / 17,88.2 \%)$. No significant difference in oxygen saturation and mean arterial blood pressure was found between the two groups.

\section{Adverse Effects}

There were no serious adverse effects from HFNC. Two subjects reported mild adverse effects from HFNC: the gas flow was too high, and the temperature was too warm. However, both of them tolerated HFNC until the end of the study. No subject was re-intubated or received noninvasive ventilation after completion of the study.

\section{Discussion}

This study is the first to evaluate the short-term physiologic benefits of HFNC compared with non-rebreathing mask in extubated subjects. The main results demonstrate that HFNC significantly improved dyspnea and physiologic variables in terms of breathing frequency and heart rate. Because the physiologic effects of HFNC need to be evaluated, it is difficult to translate them into clinically relevant significance. However, as most of the subjects preferred HFNC after finishing each intervention, we believe that the reported physiologic benefits of HFNC may have at least some clinical relevance.

The mechanisms of HFNC in improving outcomes after extubation are due to several factors. First, HFNC can provide the higher flow of gas that is necessary for extubated patients, who normally require high gas flow. Second, this device can create some PEEP with an average pressure of $1.5-7 \mathrm{~cm} \mathrm{H}_{2} \mathrm{O}^{6-10}$ depending on the flow of gas; thus, it increases the functional residual capacity and improves oxygenation. ${ }^{11}$ Third, the patients receive constant $\mathrm{F}_{\mathrm{IO}_{2}}$. Fourth, the heated humidifier can facilitate secretion clearance from the airways, protect airway epithelial cells, ${ }^{12}$ and alleviate patient discomfort. ${ }^{13}$ All of these mechanisms can explain why HFNC has better outcomes compared with conventional oxygen therapy in reducing the work of breathing and improving gas exchange in patients after extubation.

HFNC has been studied mostly in pediatric patients and has shown many benefits. ${ }^{3}$ However, literature comparing this device with conventional oxygen therapy in adult patients after extubation is scant. Tiruvoipati et al ${ }^{14}$ evaluated the efficacy of HFNC by comparing it with high-flow face mask (HFFM) in extubated patients, and they found that HFNC was as effective as HFFM in delivering oxygen in terms of gas exchange, breathing frequency, and hemodynamics. In a study by Moccaldo et al ${ }^{15}$ performed with 109 subjects who were randomized to receive air-entrainment mask or HFNC, all parameters in the HFNC group were better than those in the air-entrainment mask group, and the rate of re-intubation was lower in the HFNC group. We confirm the benefits of HFNC after extubation; however, in our study, we compared HFNC with conventional oxygen therapy (low-flow system), whereas both aforementioned studies compared HFNC with the high-flow oxygen system.

The benefits of HFNC in other patient groups have been demonstrated in many clinical studies. Sztrymf et al ${ }^{16,17}$ found that HFNC significantly reduced breathing frequency, heart rate, dyspnea score, supraclavicular retraction, and thoraco-abdominal synchrony and increased pulse oximetry in 38 ICU patients with acute respiratory failure; this improvement was observed as early as 15 min after the beginning of HFNC. This result was consistent with 

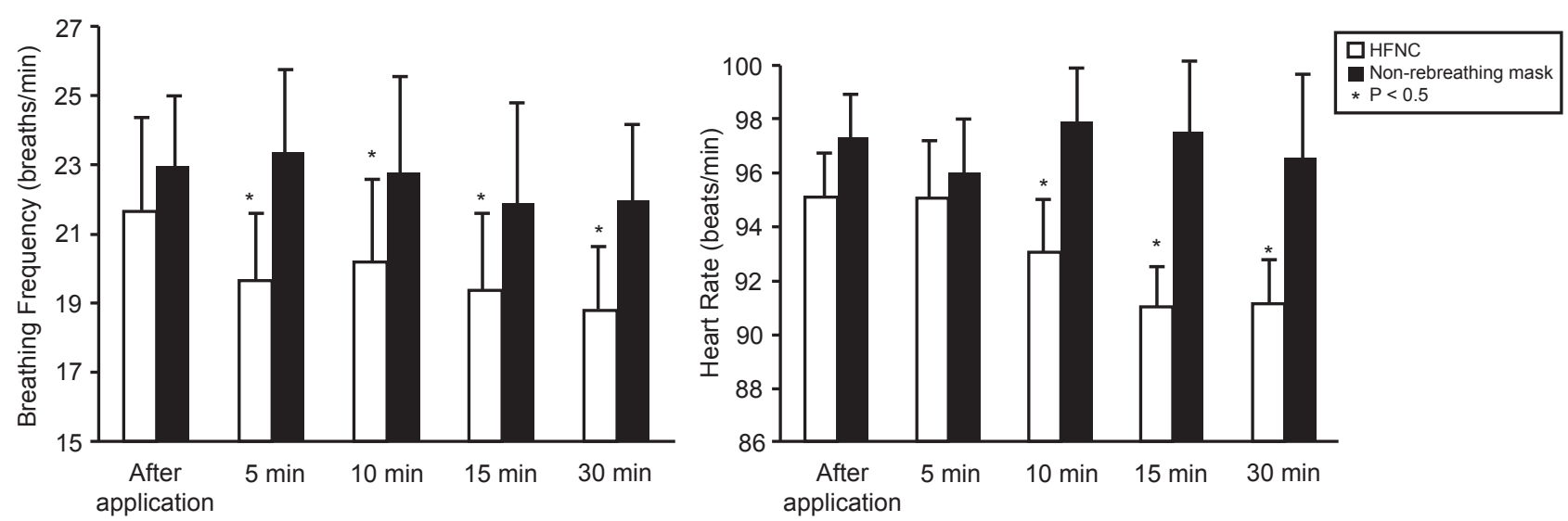

Fig. 2. High-flow oxygen via nasal cannula (HFNC) compared to non-breathing mask.

the previous study by Roca et al, ${ }^{5}$ who demonstrated that patients with acute respiratory failure who were treated via HFNC had better oxygenation and breathing frequency and were more comfortable than those treated via conventional oxygen face mask. Other potential indications for HFNC were exacerbation of COPD,${ }^{18}$ post-cardiac surgery, ${ }^{19}$ during invasive procedures such as bronchoscopy, ${ }^{20}$ and do-not-intubate patients. ${ }^{21}$

As in this study the subjects showed relatively low levels of dyspnea (dyspnea score of $<3$ points), low breathing frequency $(<25$ breaths/min), and low heart rate $(<100$ beats/min), one could argue that similar results may have been achieved with only the conventional oxygen therapy. However, it can be reasonably speculated that greater benefits may be obtained with HFNC in patients showing greater degrees of post-extubation respiratory distress.

\section{Limitations}

This study has some limitations. First, this study could not be blinded; the protocol did not have a washout period before applying each intervention; and some baseline parameters, such as level body mass index, sedation and analgesia, were missing. Second, the actual delivered $\mathrm{F}_{\mathrm{IO}_{2}}$ and total gas flow were not measured in the subjects who received the non-rebreathing mask because such a technique was difficult. Third, we did not measure the $\mathrm{P}_{\mathrm{aO}}$ / $\mathrm{F}_{\mathrm{IO}_{2}}$ ratio and $\mathrm{P}_{\mathrm{aCO}}$ during the study. This was an important limitation in comparing gas exchange and the rebound effects on $\mathrm{P}_{\mathrm{aCO}}$ from the oxygen therapy especially in COPD subjects. Fourth, the effect on sputum production or expectoration was not evaluated. In addition, we did not evaluate the cost-effectiveness of HFNC, and $30 \mathrm{~min}$ for study may not be sufficient to detect substantial physiologic differences between HFNC and conventional oxygen therapy. Thus, a large randomized study of HFNC after extubation should be performed in the future.

\section{Conclusions}

HFNC can improve dyspnea and physiologic parameters after extubation, including breathing frequency and heart rate, compared with conventional oxygen therapy. This device may have a potential role after endotracheal extubation. However, a large randomized controlled study may be required to investigate the greatest benefits of HFNC in patients after extubation.

\section{ACKNOWLEDGMENTS}

We thank Mr Suthipol Udompanthurak for his contribution to the statistical analysis.

\section{REFERENCES}

1. L'Her E, Deye N, Lellouche F, Taille S, Demoule A, Fraticelli A, et al. Physiologic effects of noninvasive ventilation during acute lung injury. Am J Respir Crit Care Med 2005;172(9):1112-1118.

2. O'Driscoll BR, Howard LS, Davison AG. BTS guideline for emergency oxygen use in adult patients. Thorax 2008;63(6 Suppl):vi1vi68.

3. Ricard JD. High flow nasal oxygen in acute respiratory failure. Minerva Anestesiol 2012;78(7):836-841.

4. Kernick J, Magarey J. What is the evidence for the use of high flow nasal cannula oxygen in adult patients admitted to critical care unit? A systematic review. Aust Crit Care 2010;23(2):53-70.

5. Roca O, Riera J, Torres F, Masclans JR. High-flow oxygen therapy in acute respiratory failure. Respir Care 2010;55(4):408-413.

6. Parke R, McGuinness S, Eccleston M. Nasal high-flow therapy delivers low level positive airway pressure. Br J Anaesth 2009;103(6): 886-890.

7. El-Khatib MF. High-flow nasal cannula oxygen therapy during hypoxemic respiratory failure. Respir Care 2012;57(10):1696-1698.

8. Groves N, Tobin A. High flow nasal oxygen generates positive airway pressure in adult volunteers. Aust Crit Care 2007;20(4):126131.

9. Parke RL, McGuinness SP. Pressures delivered by nasal high flow oxygen during all phases of the respiratory cycle. Respir Care 2013; 58(10):1621-1624.

10. Ritchie JE, Williams AB, Gerard C, Hockey H. Evaluation of a humidified nasal high-flow oxygen system, using oxygraphy, cap- 


\section{High-Flow Nasal Cannula After Extubation}

nography and measurement of upper airway pressures. Anaesth Intensive Care 2011;39(6):1103-1110.

11. Riera J, Pérez P, Cortés J, Roca O, Masclans JR, Rello J. Effect of high-flow nasal cannula and body position on end-expiratory lung volume: a cohort study during electrical impedance tomography. Respir Care 2013;58(4):589-596.

12. Chidekel A, Zhu Y, Wang J, Mosko JJ, Rodriguez E, Shaffer TH. The effects of gas humidification with high-flow nasal cannula on cultured human airway epithelial cells. Pulm Med 2012;2012:380686.

13. Chanques G, Constantin JM, Sauter M, Jung B, Sebbane M, Verzilli D, et al. Discomfort associated with underhumidified high-flow oxygen therapy in critically ill patients. Intensive Care Med 2009; 35(6):996-1003.

14. Tiruvoipati R, Lewis D, Haji K, Botha J. High-flow nasal oxygen vs high-flow face mask: a randomized crossover trial in extubated patients. J Crit Care 2010;25(3):463-468.

15. Moccaldo A, Vaschetto R, Bernini V, Antonicelli F, Festa R, Idone F, et al. Ossigenoterapia dopo estubazione: confront tra sistema ad alti flussi (Optiflow) e maschera venture. Minerva Anestesiol 2011; 77(2 Suppl):169. Article in Italian.

16. Sztrymf B, Messika J, Mayot T, Lenglet H, Dreyfuss D, Ricard JD. Impact of high-flow nasal cannula oxygen therapy on intensive care unit patients with acute respiratory failure: a prospective observational study. J Crit Care 2012;27(3):324.e9-324.e13.

17. Sztrymf B, Messika J, Bertrand F, Hurel D, Leon R, Dreyfuss D, Ricard JD. Beneficial effects of humidified high flow nasal oxygen in critical care patients: a prospective pilot study. Intensive Care Med 2011;37(11):1780-1786.

18. Austin MA, Wills KE, Blizzard L, Walters EH, Wood-Baker R. Effect of high flow oxygen on mortality in chronic obstructive pulmonary disease patients in prehospital setting: randomised controlled trial. BMJ 2010;341:c5462.

19. Corley A, Caruana LR, Barnett AG, Tronstad O, Fraser JF. Oxygen delivery through high-flow nasal cannulae increase end-expiratory lung volume and reduce respiratory rate in post-cardiac surgical patients. Br J Anaesth 2011;107(6):998-1004.

20. Lucangelo U, Vassalo FG, Marras E, Ferluga M, Beziza E, Comuzzi $\mathrm{L}$, et al. High-flow nasal interface improves oxygenation in patients undergoing bronchoscopy. Crit Care Res Pract 2012;2012: 506382.

21. Peters SG, Holets SR, Gay PC. High-flow nasal oxygen therapy in do-not-intubate patients with hypoxemic respiratory distress. Respir Care 2013;58(4):597-600.

This article is approved for Continuing Respiratory Care Education credit. For information and to obtain your CRCE

(free to AARC members) visit

www.rcjournal.com 